CALEFDOSCOPIO

14

JULIO - DICIEMBRE 2003

\section{La patria centroamericana en la prensa política guatemalteca: continuidades $y$ rupturas en El Amigo de la Patria y El Unionista (1820-1920)}

TERESA GARCÍA GIRÁLDEZ

Universidad Autónoma de Madrid

INTRODUCCIÓN

Dentro del grupo que conforma la Generación del 20 guatemalteca hay algunos intelectuales que, desde las páginas de los periódicos, defendieron la idea de la unión de las repúblicas centroamericanas como idea de regeneración nacional, social e individual. El Unionista salió a la luz para hacer propaganda del programa de la sección guatemalteca del Partido Unionista y reavivó el viejo proyecto de Valle y de Bolívar de la Patria Grande centroamericana como modelo de nación incluyente. A través de la estructura en ligas de obreros y de estudiantes, este órgano de difusión del Partido Unionista encontró el modo de hacer proselitismo con campañas en contra del régimen. Publicaba, a propuesta de las ligas obreras, una sección llamada "las conferencias dominicales", donde se resumía la elaboración teórica de intelectuales, profesionales, artesanos y obreros desde diversas y variadas perspectivas, en defensa de la necesidad de la unión; así también daba cuenta de convocatorias a actos públicos, listas de las adhesiones o denuncias de la represión del gobierno de Estrada Cabrera contra miembros o simpatizantes del partido.

En Centroamérica, en particular en Guatemala, en la oposición a la dictadura de Estrada Cabrera resulta complejo distinguir la línea divisoria en el pensamiento unionista entre quiénes eran liberales y conservadores, puesto que juntos libraron batallas en esta ocasión. 
El "ideal unionista" constituía el nexo entre ambas tendencias, las cuales apelaban a Valle, Bolívar, Morazán, Jerez o Barrios como promotores y seguidores de este proyecto nacional. Sin embargo, los referentes explícitos eran Valle como aglutinador de tendencias y Morazán como patriota pragmático; la figura de Barrios era más polémica y no la compartían todos los unionistas, probablemente porque alguna de sus reformas había chocado contra los intereses de algunos de ellos.

El Unionista fue objeto de críticas de otros periódicos y se le acusó de conservador, lo que rememoraba los ataques que padecieron $\mathrm{El}$ Amigo de la Patria y su director Valle.' Correspondían también, como aquéllos, a momentos de transición política; a la clausura de dos regímenes despóticos: el colonial y el liberal cabrerista respectivamente, situación similar que vivía toda Centroamérica. Las tendencias opuestas utilizaban la prensa, ahora como en el pasado, para generar un debate público en el que se dirimían las diferencias. Indudablemente los ataques que desde otros periódicos, como Excélsior, El Diario de Centroamérica, El liberal, etc. se lanzaban contra El Unionista nos recuerdan los que se hicieron desde las páginas de El Editor Constitucional y El Genio de la Libertad de P. Molina contra El Amigo de la Patria, cuando aquéllos tachaban a Valle, su director, de conservador, ultramontano o "cachureco"2; en una palabra, de antiliberal. Ahora son los propios unionistas los que acuden a la prensa de Molina y a los héroes de la patria como Jerez, Morazán o Barrios para rebatir qué entienden por auténtica libertad liberal, que libertades se han coartado, y entre estas libertades, la de prensa más que ninguna otra.

Algunos de los intelectuales más representativos de El Unionista integraron un fragmento de red social ${ }^{3}$ que formó el complejo entramado de la "familia" unionista, aun más allá del parentesco. Se

Teresa García Giráldez, "Nación cívica, nación étnica en el pensamiento político centroamericano del siglo XIX", en M. Casaús y O. Pelárz (eds.), Historia intelectual de Guatemala, CEUR-AECI-UAM, Guatemala, 2001, pp. 51-117.

El Unionista, año l, no 4, lunes 19 de enero de 1920.

M. Bertrand, "De la familia a la red de sociabilidad", en Revista Mexicana de Sociología, no 2, vol. 61, abril-junio, 1999, p. 108. 
entiende que el proyecto subyacente defendía el ideal centroamericano como guía de progreso no sólo de Centroamérica sino de toda la humanidad, fundado no tanto en el avance material y científico, sino en la regeneración y "redención" del indio y de la nación, pensamiento que había cobrado fuerza en la primera mitad del siglo XX.

El periódico reflejaba el pensamiento de una parte de la élite intelectual guatemalteca que capitaneaba la defensa de un viejo ideal federal y recurría a elaboraciones teóricas de indudable calidad, valiéndose de las que anteriormente habían propuesto J. C. del Valle y P. Molina en las páginas de El Amigo de la Patria, El Editor Constitucional y El genio de la libertad. El Unionista se sintió involucrado en la formación de una opinión que había de llevar a la elaboración de un proyecto de nación y dedicó sus energías, en ese momento coyuntural, a conformar un movimiento para derrocar la dictadura de Estrada Cabrera. El amplio espacio dedicado a la Patria grande en El Amigo de la Patria proporciona el contenido programático e ideológico del que se iba a beneficiar El Unionista. Vamos a analizar este periódico circunscribiéndolo a la etapa previa al derrocamiento de la dictadura de Estrada Cabrera (de diciembre de 1919 a abril de 1920), por considerar que es un momento de búsqueda de adhesiones en función de continuidades y alianzas entre el mayor número posible de ciudadanos.

Los temas de mayor interés, en este primer cuarto del siglo XX seguían siendo el debate sobre la Patria Grande y la definición de su forma y contenido -federal o confederal, centralizada o descentralizada. Frente a los unionistas se colocaban quienes sostenían la separación en repúblicas o la necesidad de mantener el status quo. Se debatía la ventaja o no de integrar en el proyecto unitario a Panamá; el papel que habían de jugar los países vecinos, México y Estados Unidos, o entidades como la Oficina Internacional Centroamericana. En cuanto a la primera cuestión, Honduras era partidaria de la forma confederal, mientras que los otros países propugnaban una unión federal; Costa Rica explícitamente no estaba interesada en este proyecto, salvo por lo que hacía referencia a la necesidad de mantener la seguridad colectiva de la región.

Por lo que se refiere al segundo tema, la propuesta de Nicaragua de invitar a Panamá al concierto centroamericano como un miembro más, se vio acompañada de la sugerencia de que fuera este país la

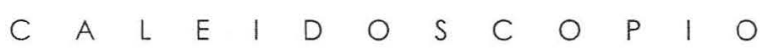


sede alternativa de las reuniones frente a la de Estados Unidos. Las propuestas no fueron acogidas favorablemente por Honduras, que ni lo consideraba un Estado soberano ni su territorio apropiado para sede de reunión de los países centroamericanos ${ }^{4}$ y, sobre todo, temía que se debilitara la estructura de la unión, si se celebraban los congresos fuera del territorio de los cinco estados centroamericanos. En lo referente al tercer aspecto, El Salvador fue quien sugirió, en 1918, que Estados Unidos y México participaran como mediadores en la unificación, como lo habían hecho en los Pactos de Washington de 1907. Nicaragua apoyaba también esta propuesta, el cual no veía con buenos ojos a Costa Rica. En cambio, este país y Honduras se opusieron rotundamente, aun cuando Estados Unidos no reconocía a Costa Rica como Estado soberano. ${ }^{5}$

A mediados del año 1920, El Salvador proponía que se celebrase una Conferencia de Plenipotenciarios Centroamericanos para revisar los Pactos de Washington y preparar un plan de unión política de Centroamérica. La Oficina Internacional Centroamericana fijaba para el mes de diciembre dicha reunión. Empezaron las presiones a favor de la Unión: el alcalde hondureño de Comayagua se dirigió a su homónimo de la capital guatemalteca para que apoyase el proyecto de unión y éste decidió convocar un congreso municipal centroamericano en La Antigua, para circunscribir a la Unión Centroamericana dentro de su propio territorio. La Asamblea de El Salvador aprobaba el 6 de julio de 1919 dos decretos unionistas, uno de los cuales autorizaba la gestión ante los demás gobiernos de Centroamérica en torno a la posibilidad de poner en vigor la Constitución de la República mayor de $1848 .{ }^{\circ}$ Sin embargo, la atmósfera

\footnotetext{
4 El artículo 136 de su Constitución permitía la intervención de Estados Unidos.

5 W. Wilson consideraba que Federico Tinoco había atacado la Constitución dando un golpe de estado, aunque fuera indoloro. Tampoco Emiliano Chamorro, presidente de Nicaragua desde 1917, reconocía al gobierno costarricense e incluso propuso a Honduras que se invadiera este país con objeto de derrocar a Tinoco.

- Conferencia de Plenipotenciarios Centroamericanos celebrada en San José de Costa Rica del 4 de diciembre de 1920 al 19 de enero de 1921, Imprenta Nacional San José Costa Rica, 1921.
} 
estaba cargada a principios de 1920 y parecía propicio que prosperaran las negociaciones unitarias amistosas entre los países centroamericanos.

El Unionista: fragmento de red

La generación joven de estudiantes centroamericanos de secundaria decidió en 1899 formar la sociedad "El Derecho", con objeto de sensibilizar a la población sobre la necesidad de eliminar las fronteras y volver al ideal de un solo pueblo centroamericano; pretendían con ello crear espacios de difusión y de socialización en los que los estudiantes centroamericanos debatieran e intercambiaran ideas sobre proyectos comunes. Capitaneaba este grupo el centroamericanista Salvador Mendieta y lo integraban entre otros, Manuel Cobos Batres, Eduardo Camacho, José Azmitia, Joaquín Rodas, etc. En mayo de 1919 dieron carta de ciudadanía a una segunda convención ${ }^{7}$ de la que surgió el Partido Unionista, ${ }^{8}$ que alegaba no sentirse representado ni por los partidos existentes ni por los gobiernos y sus gobernantes, a quienes achacaban la instrumentalización del ideal unionista en beneficio propio. Este grupo de ciudadanos sin distinción de ideología política ni creencias religiosas había constituido el Partido Unionista para trabajar por medios pacíficos y legales por la unión de Centroamérica. Consideraban que había llegado la hora de que todos los centroamericanos formasen la Patria Grande, donde imperase la paz, el derecho y la justicia. Era también un proyecto de felicidad y a la prensa correspondía transmitir esta verdad y contribuir a alcanzarla.

El Unionista salió a la luz el 25 de diciembre de 1919; se definía independiente y órgano del partido de su mismo nombre, ponía en

7 Animado por los sermones del Obispo José Piñol y Batres, que tuvo que exiliarse en EE.UU. Ernesto Viteri Bertrand, El Pacto de Unión de 1921: sus antecedentes, vicisitudes y la cesación de sus efectos, Editorial e Imprenta Apolo, Guatemala, 1976.

8 Organizado dos meses más tarde entre los anteriores, Emilio Escamilla, Julio Bianchi, Tácito Molina Izquierdo, Federico Castañeda Godoy y Adalberto A. Saravia. 'T. Molina fue quien redactó el Acta fundacional. 
conocimiento de los lectores el acta de organización del partido, "Acta de los tres dobleces", y convocaba a debatir el ideal unionista. Se proponía como medio de propaganda para atraer al ideal de la unión al mayor número de lectores. Sólo bajo este perfil se puede comprender la contradicción entre lo independiente y lo orgánico de la propuesta que rezaba en su cabecera. Algunos de los articulistas eran miembros de las redes familiares tradicionales, liberales y conservadoras; ${ }^{9}$ otros pertenecían a las ligas obreras y artesanas, ${ }^{10}$ otros eran estudiantes y todos ellos colaboraban como comentaristas. Bajo la dirección de A. Saravia, E. Escamilla, J. Azmitia y otros, los articulistas más relevantes de este periodo, además de los propios directores, fueron: T. Molina Izquierdo, F. Castañeda Godoy, R. Castellanos, J. García Granados, F. Fajardo, L. A. Paz y Paz, C. Marroquín Rojas; Nicolás Reyes, J. V. Dardón, Ignacio Rodríguez Medina o F. Morán G. en representación de los obreros y artesanos.

La idea de regenerar la sociedad permeaba las páginas de El Unionista y la lucha por este ideal de regeneración humana era sentida como una obligación moral de los unionistas; se entendía como unión de esfuerzos para combatir la ignorancia, la mentira y la ambición de cada país con los recursos de toda Centroamérica. Dice J. Bianchi que el modo de construir la historia de la patria grande de los mayores" es

La comisión organizadora está formada por: Luis P. Aguirre, Leopoldo Alcaín, Víctor M. Alcántara, José Alvarado, Isaac Archila, Vicente Arévalo, José Azmitia, que sucederá en la dirección a partir de febrero de 1920, José Barillas F., Luis Beltranena, Eduardo Camacho, Federico Castañeda G., Eduardo Castellanos C., Mariano Castillo A., Manuel Cobos Batres, Emilio Escamilla (director) , Francisco Fajardo, Enrique Forno, Jorge García Granados, Ramón Godoy, J. Miguel Leal A., B. de León G., Salvador Matheu, Alberto Mejicanos, Tácito Molina I., Guillermo Rosales A., Juan Rosales Alcántara, Adalberto A. Saravia (secretario general), José Ma Saravia, Francisco Villacorta y Juan Vicente Villacorta. El Unionista, año I, jueves 25 de diciembre de 1919.

I. Demetrio Ávila, Damiano Caniz, Eusebio Castillo, Diego Deán Gálvez, J.A. Estrada, Rafael Foronda, Rafael González, O., Saturnino González, Agustín Hernández C., Ernesto C. López M., José Antonio López L., Juan H. Ortiz, Silverio Ortiz, Francisco Rodríguez, Tereso A. Rojas, Bernabé Salazar, Sabino A. Saucedo, Miguel Tizón, Teódulo Vega M. y Pioquinto J. Velázquez. El Unionista, año l, jueves 25 de diciembre de 1919.

1 El Unionista, año $1, n^{\circ} 4$, lunes 19 de enero de 1920. 
obra de la juventud, pues quién si no ella es el mejor motor de la regeneración y el progreso. Conviene recordar que también Rodó, Ingenieros, Gamio, Ortega y Gasset y otros autores ejercían una gran influencia en el continente americano y depositaban en las generaciones jóvenes los valores más creativos y positivos de la humanidad, los propósitos más honrados, los anhelos más legítimos y los ideales más altos. La juventud para estos unionistas era la encargada de forjar la patria con los ideales de fraternidad, redención y progreso. Así lo aclaraba R. Castellanos cuando presentó su adhesión como miembro del "Club Unionista Universitario"; sostenía que era un ideal que el Partido Unionista compartía con la juventud, un ideal que se podía alcanzar si se utilizaban los medios legales, porque ponía por encima de credos políticos y religiosos el amor a la patria centroamericana y el sentimiento patriótico, del que los jóvenes no podían marginarse. ${ }^{12}$

12 Las miembros son: Raúl Alarcón S., J.E.Alvarado, Ramiro Alvarez A. Rafael Álvarez B., Miguel Alvarez Ll., Pedro Amézquita, Flavio Andrade M., Enrique Andreu C., Alfredo Asensio, M. Ángel Asturias, J.E. Barrios R., M. Beltranena Sinibaldi, E. Beltranena S., Juan J. Beltranena y S. Luis Barrutia, J.J. Bonilla B., A. Bustamante H., Raúl Caballeros Marroquín, Víctor Manuel Calderón, Arturo Callejas, Romeo G. Carranza, Matías Castellanos H., Rafael Castellanos S., Roderico Cifuentes M., A. Cordón H., Antonio Cruz, Valentín Dávila H., Fernando Díaz, E. Echeverría A., Oscar Humberto Espada, E. Estrada, Vicente Fernández, F. Fernández G., M.A. Flores, Ramiro Fonseca P., Guadalupe Franco R., Julio Fuentes Novella, F. García, Salvador García Iglesias, Roberto Gómez S., Tomás González, F. González Sierra, Justo Rufino Guerra, Silverio Guerra, Carlos Herrarte, Angel M. Iturbide, Carlos Klusman, A. Laparra, José Luis Lemus, Alberto Lemus A., Manuel de León Cardona, Pedro M. Letona, Gregorio López, Everildo Mansio, H. Marroquín Rojas, Antonio Méndez H., I. Alfredo Méndez, José Milla, Héctor Montano H., Rafael Mora, Max Moreno Palomo, A. Fuentes Novella, Rodrigo Ochoa B., Alfredo Orantes O., Carlos Padilla H., Adolfo Paíz A., José Palomo F., Manuel V. Paz S., Alberto Paz y Paz, Domingo E. Palacios, Arturo Peralta A., Arturo Portilla, Tomás Posadas O., M. Ramírez Ll., Eduardo Rivera M., Luis Rivera I., Manuel ma. Rivera V., Fernando Rosales G., Jorge Rubio Asturias, Julio Rubio Muñoz, Max. Salguero B., Hernán M. Sandoval, Melitón San Martín, José Santa Cruz, Francisco Sarti, Alfredo Valle C., F. Villagrán, Moisés Villagrán M., Agripino Zea, M. Zebaldúa H., El Unionista, año l, nº 5, martes 20 de enero de 1920. 
Ese ideal era además un compromiso histórico con las generaciones futuras, las cuales juzgarían mañana lo que se ha hecho hoy, la herencia perdida y la que se recupere en el futuro. La juventud está vigilante, ha sido siempre centinela de la libertad, el derecho y la justicia. En los pueblos que se empequeñecen la juventud sigue siendo grande y aúna sus esfuerzos con todos los "buenos ciudadanos que son los verdaderamente patriotas", para reconstruir la Patria centroamericana, la Patria que legaron los mayores: Unida, Grande y Soberana. Luis Beltranena llega más allá en su idea y propone llanamente alterar las instituciones; "cuando las autoridades de la República no consigan la felicidad de sus ciudadanos o se opongan a ella, es un deber removerlas" ${ }^{13}$ Éste era el sentir generalizado, por esto, una semana antes del derrocamiento de Estrada Cabrera salía a la luz El Estudiante ${ }^{14}$ con un artículo de Miguel Ángel Asturias en el que abiertamente pedía la dimisión de Estrada Cabrera.

Ante este tenor de cosas, en El Unionista del periodo estudiado, antes del derrocamiento de Estrada Cabrera (diciembre 1919-abril

El Unionista, año I, no 7, jueves 22 de enero de 1920.

Eran redactores: Eugenio Silva Peña, José Luis Valcárcel, Ernesto Viteri Bertrand y Terencio García. El Estudiante, jueves 1 de abril de 1920. En la discusión del derrocamiento no participaron ni Arturo Ubico (presidente), ni José Antonio Mandujano ni Mariano López Pacheco (vicepresidentes). Presidió la sesión José A. Beteta como Presidente de la Comisión de Gobernación; Carlos Herrera y Adrián Vidaurre como Vicepresidentes, León de León Flores como secretario titular y José Antonio Villacorta, Santiago Romero y Alberto Madrid como secretarios interinos. Presentó la denuncia de incapacidad mental el general, Subsecretario de Guerra y diputado losé $\mathrm{M}^{\mathrm{a}}$ Letona. Firmaron el Acta de destitución: Manuel Arroyo, Salvador Ortega, Celso Escobar, Norberto Gálvez, Alberto Madrid y Carlos Padilla Matute; además de los médicos Carlos A. Murillo, Fernando Iglesias, Ricardo Alvarez, Antonio Valdeavellano, Eduardo Lizarralde, Rafael, Pacheco Luna, Federico Azpuru España, José Ma Palacios, Francisco Ramírez Llerena y Alfredo Castellanos. No lo firmaron porque estaban ausentes: Alfonso Asturias, Alfredo Palomo Rodríguez, Angel $\mathrm{M}^{\mathrm{a}}$ Bocanegra, Arturo Ubico, Canuto Castillo, Enrique Heussler, José Antonio Mandujano, Jesús C. Rivas, Jorge Ubico, José Barillas V., Lizardo Estrada G., Manuel Arana, Manuel Ma Girón, Mariano C. Reina, Mariano López Pacheco, Máximo Soto Hall, Ricardo C. Castañeda, Ricardo Sánchez O., Salvador Girón y Virgilio Rodríguez Beteta. Ernesto Viteri Bertrand, El Pacto de Unión de 1921: sus antecedentes, vicisitudes y la cesación de sus efectos, Editorial e Imprenta Apolo, Guatemala, 1976. 
1920), se pueden observar algunos de los siguientes aspectos.

\section{La lucha contra los regímenes dictatoriales y el imperialismo}

Desde el primer número hay referencias explícitas a la continuidad histórica entre lo que revelaba El Editor Constitucional y lo que se planteaba ahora. Tácito Molina recuerda en el primer número de El Unionista las circunstancia en las que había nacido aquel periódico y la función que había desempeñado en la caída del régimen colonial. El ataque a las dictaduras se desarrollaba con una amplia y detallada crónica de las violaciones de los principios constitucionales. Además, se proporcionaban listas de las abusos perpetrados por las autoridades contra los unionistas. Por otra parte, se reforzaba el interés de los unionistas por desechar explícitamente cualquier tipo de violencia verbal o armada en las reuniones del movimiento.

Se seguían las enseñanzas de S. Mendieta y se hacía campaña a favor de las libertades. De los regímenes que ambos criticaban, se señalaban en concreto los recortes a la libertad de asociación y de prensa. Molina aprovechaba este parangón para subrayar el papel civilizador de la prensa como motor de la educación del "pueblo libre" en su lucha por convertirse en pueblo soberano: sólo quien se sabe ciudadano y conoce sus derechos puede opinar sobre el ejercicio y el respeto de los mismos. El papel de la prensa es ser un instrumento que coadyuva a enriquecer el conocimiento de la gente común, de ahí la importancia de su libertad e imparcialidad. Además de las libertades de prensa, de asociación y de participación política, es necesaria la reforma de las prácticas electorales, mediante la creación de comisiones electorales que sean imparciales, sin recurrir a la violencia ni a la conspiración, siendo aquéllas las únicas armas legítimas de lucha para alcanzar el pleno ejercicio de estos derechos ciudadanos. Los gobiernos de caudillaje habían arrebatado la libertad con el recurso de la fuerza, amordazaron a la prensa para que no se oyera la voz del patriotismo; por causa de la mala prensa se negaron al pueblo sus derechos y se usurpó su soberanía. Así, la prensa y los conservadores habían acabado halagando a las dictaduras, aunque ahora había llegado el momento de la redención del pueblo centroamericano. Los hombres libres, manejando la prensa, sabrían difundir la luz al pueblo soberano

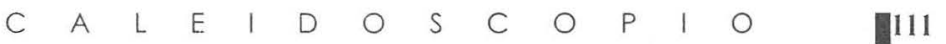


y le enseñarían el derecho, la justicia y la libertad.

\section{La reconstrucción de la Patria Grande}

La continuidad de la obra unificadora precedente, constatada desde los primeros números de El Unionista, pretendía demostrar la perdurabilidad del proyecto de nación centroamericana iniciado a principios del siglo XIX, el cual se mantenía vigente a pesar de las circunstancias adversas por las que se atravesaba. El unionismo era un sentimiento fraternal de solidaridad entre pueblos con más elementos de cohesión que divergencias profundas; era además un sentimiento de pertenencia a una entidad supranacional, la Patria Grande; y de posesión, porque se era capaz de ser leal hasta el límite. Se prefería el término patria -el sentimiento de patriotismo- al de nación, país o estado; pero patria significaba también nación y así figuraba a lo largo de las páginas de El Unionista. Es la Patria Grande el ideal más generoso y noble que cada uno de los centroamericanos está llamado a reconstruir, en el sentido que la entendían Valle y Bolívar, el ideal por el que lucharon y murieron Morazán, Jerez y Barrios. ${ }^{15}$ Sin que se considerasen todos los proyectos iguales ni movidos por los mismos intereses, se subrayaba que algunos centroamericanos no lo comprendían, por ejemplo, el proyecto unionista de J. R. Barrios, porque estaba demasiado centralizado en la persona, miraba más al hombre que a la idea. En cambio, el proyecto unionista que se proponía ahora en Guatemala daba prioridad a las ideas y no necesitaba caudillos que las divulgasen; aunque se sostenía que se estaba bajo el liderazgo de Salvador Mendieta. ${ }^{16}$ En los primeros números del periódico no hay ningún artículo de este autor (de diciembre de 1919 hasta marzo de 1920), como si se quisiese mostrar, con esto, que se tratara de una idea genuina.

15 Humberto Reyna Barrios, "Discurso", en El Unionista, año I, n 17 , martes 3 de febrero de 1920.

16 Salvador Mendieta, Exposición presentada a la Asamblea nacional Constituyente de la República de Centroamérica. Managua, 1921 y Alrededor del problema unionista de Centroamérica, Barcelona, 1926. Originario de Nicaragua. 
Los sentimientos unionistas, además de expresiones de lealtad a la Patria, eran manifestaciones antiimperialistas y antioligárquicas; ${ }^{17}$ se sentía el deber moral centroamericano de estar dispuesto al sacrificio de la propia vida, si fuera menester. La idea de la unión en Centroamérica era también percibida como proyecto a largo plazo, lleno de obstáculos; una idea que para muchos unionistas fluía del orden divino y de los antepasados, de ahí que la lealtad pudiera implicar aquel sacrificio sublime. De nuevo se volvía al concepto de patria como pertenencia a la tierra en la que se ha nacido y de patriotismo como lealtad a esa tierra natal: "la Patria, deidad que representa materialmente para el hombre, el suelo inolvidable en que vio la luz primera". Con un sentido de la lealtad bien definido: "jamás puede prescindirse de amarla [...] por amarla, servirla y defenderla, los caracteres fuertes y nobles renuncian a su bienestar, ofrendan sus caudales y sacrifican hasta a sus mismos hijos. " ${ }^{18}$ Para desarrollar este noble sentimiento no era necesario, según este periódico, usar la fuerza, porque el fundamento de la unión centroamericana eran el amor, la conveniencia moral -no utilitaria- de las partes y el afán de perfección que está sobre la idea de creación de un pueblo homogéneo. La Patria era de todos porque las ideas no podían ni pueden ser propiedad privada de nadie. Se hallaba, llegado el momento, incluso por encima del individuo, como decía J. Marcos Leiva citando a Herrera: "hay que ser patriota más que ciudadano, pues toda grande idea que se ha llevado a cabo ha necesitado de sacrificios".

Lo novedoso de la propuesta unificadora radicaba en presentarse como movimiento social; esta vez no derivaba del miedo a una agresión exterior ni partía de los gobernantes, sino de la gente, de las inquietudes "de la parte consciente de nuestros pueblos", que son los encargados de popularizar las propias ideas, preparar al pueblo para la Unión y hacer que comprenda sus ventajas para que el deseo nazca de él, para que la idea se lleve a cabo sin recelos ni resentimientos mutuos y para que aprendan a posponer los localismos mezquinos a la magna idea de la unión. Al mismo tiempo, se trataba de hacerle

\footnotetext{
17 G. Cardoza, El Unionista, año I, n 15, sábado 31 de enero de 1920.

18 Ignacio Rodríguez Medina, El Unionista, año I, nº 3, sábado 17 de enero de 1920.
} 
comprender las inmensas ventajas de formar una nación grande cuya voz fuera escuchada y atendida en los foros mundiales y reflejada en los tratados de las naciones, que permitiera de esa manera cambiar la triste opinión que se tiene de las instituciones y del modo de vivir centroamericano fuera de sus fronteras; haciendo ver que se era capaz de concebir ideales, de ponerlos en práctica sin conmociones sangrientas y de sostenerlos sin ideas mezquinas. ${ }^{19}$

Era un proyecto incluyente y homogeneizador de ciudadanía al que debía aspirar todo el mundo, "sin distinción ni de castas ni de credos" ${ }^{20}$ No confundía, no separaba, estaba abierto a todo el mundo, siempre que no se persiguieran intereses egoístas ni escisionistas. Los intereses personales habían sido históricamente los que dominaron al interés general y originaron la fractura de la República Federal, de 1824 a 1838 , en cinco repúblicas que empobrecieron a Centroamérica. La labor unionista no contemplaba la exclusión de ninguna clase social porque era "concordia que une a las diversas clases sociales", ${ }^{21}$ ya que todos estaban llamados a contribuir a esta tarea creativa, ennoblecedora y voluntariosa, de la que dependía la prosperidad de la región y de sus habitantes. Quizá los únicos excluidos pudieran ser: "los indiferentes, los castrados, los inermes y los estúpidos." 22

El proyecto buscaba la homogeneidad cívica y no contenía ninguna referencia a la necesidad de uniformidad étnica, cultural ni de género. Las pocas referencias al indígena o a la mujer en las páginas de $\mathrm{El}$ Unionista en el periodo analizado son en términos de ciudadanos a quienes se reconocen cualidades y limitaciones, derivadas de abusos y prepotencias de algunas autoridades. En las contadas ocasiones en las que figuran los indigenas, se subrayan algunos estereotipos en los que resalta el origen social de los mismos, sosteniendo la idea de que

El Unionista, año I, nº 2, jueves 15 de enero de 1920.

20 Según palabras de José Humberto Reyna Barrios, que se declaraba además liberal por herencia y por ideas. El Unionista, año I, n 4, lunes 19 de enero de 1920.

21 Discurso del ciudadano bachiller don Rafael Castellanos, el 18 de enero de 1920 al hacer entrega del Acta de adhesión del "Club Unionista Universitario" al Comité Ejecutivo del partido Unionista. El Unionista, año I, n 5, Guatemala, martes 20 de enero de 1920.

22 El Unionista, año l, no 8, viernes, 23 de enero de 1920. 
se trata de esa pobre gente maltratada -"indígenas decrépitos $|\ldots|$ infelices vapuleados"- en un momento en que están realizando protestas contra el esquilmo y las descaradas exacciones de que son objeto -se les exonera del servicio militar por dinero, están sujetos a la obligación de los mandamientos, etc. Cuando se compara la situación económica por países y gobiernos de la región se subraya que Guatemala está más adelantada que Nicaragua, Honduras o incluso que México; pero también se aprovecha la otra cara del desarrollo para denunciar que se ha obligado a los indígenas a emigrar y se ha mermado su número:

por miles han muerto y emigrado nuestros indígenas, buscarido refugio y amparo en las vecinas repúblicas, de la tiranía de los caciques departamentales, y éstos se han reído y mofado de todas las quejas, porque se saben inamovibles [...] pueden por su parte saciar sin restricciones sus instintos salvajes en los indefensos habitantes. ${ }^{23}$

El tema de la mujer se trata con cierto cuidado, por una parte se recordaba que también recibían un trato desigual en el trabajo y se abusaba de ellas, por ejemplo cuando por dinero se les podía eximir de ciertos servicios (el de moledoras en los cuarteles). Por otra, sin embargo, se resaltaba su papel emprendedor y valiente, su buena labor dentro de la familia, como madres o esposas abnegadas. ${ }^{24}$

La pluralidad que cobijaba la idea unionista, el variado crisol de sus miembros, distintos por ideología, edad, creencias religiosas, condición cultural, económica, social y de género era, según Barillas Fajardo, lo que daba fuerza al unionismo. La razón más imperiosa de que no se hiciera referencia a la homogeneización étnica era porque la Patria se planteaba en términos de inclusión en la gran familia, como

23 Emilio Escamilla sostenía que en Guatemala la producción de café oscilaba entre los 800,000 y 600,000 quintales; la producción del azúcar era de 350,000 quintales, mientras en Nicaragua, con menor población y extensión, era de unos 500,000 quintales y en Cuba era muy superior; la exportación de maíz estaba prohibida; se traía ganado de Honduras y México. Cfr. "Nuestra labor interna", en El Unionista, año $1, n^{\circ} 13$, jueves 29 de enero de 1920.

24 El Unionista, año I, nº 25, viernes 12 de febrero de 1920. 
decía J. C. del Valle, ${ }^{25}$ en donde las diferencias son relativamente poco relevantes. Decía Eduardo Mayorga:

Unidos por el sentimiento de la sangres, que es una en nuestras venas; por identidad de costumbres y credos religiosos, por el vínculo sonoro del idioma; por los heroísmos pretéritos y gloriosos de nuestros abuelos; y lo que es más aún, por un mismo y alto destino que cumplir: la Unión se impone. Abatamos las fronteras del egoísmo lugareño, y en un acto supremo de concordia y fraternidad, aunemos todos los vigores dispersos del Istmo en pro de nuestros ideales, que muy bien pueden condensarse en una sola palabra: iPATRIA! ${ }^{26}$

La centroamericana era una gran familia, la hermandad de la patria grande que "no ve partidos, que no ve enemigos, sino hermanos [recuerda a la] compañía de socios, familia de hermanos", de la que hablaba J. C. del Valle ${ }^{27}$; estaba unida por lazos de conveniencia, de amor, de cordura y de patriotismo, protegida por Dios bajo el emblema de la libertad. Los pueblos de Centroamérica eran uno: una naturaleza, un idioma, una religión, unas costumbres; eran todos hijos de la misma madre, pero separados por la ambición de los malos ciudadanos que cubren sus instintos con bellas palabras y falsas promesas.

Se consideraba que el problema de la reconstrucción de la nacionalidad común era lo más trascendental e importante del momento y que los centroamericanos eran conscientes de la urgencia, en los términos que planteaba lúcidamente B. Echeverría:

Será una unión estable porque se harán acuerdos pactados y sólidos fundados en profundas convicciones; justa porque se basa en dar a cada uno lo que le corresponde, con la buena fe y sentimientos patrióticos; popular porque contraria a los sectarismos; y con visión internacional y además será conveniente para Guatemala, porque la une con sus hermanas, haciéndola fuerte y feliz. Será estable porque toda relación, sea jurídica o social, para que produzca el bienestar de todos los asociados y el fruto que se espera, habrá de llevar en sí los caracteres de sinceridad y desinterés que garanticen su larga duración; justa porque indefectiblemente debe toda unión basarse en principios de equidad y de altruismo,

25 T. García Giráldez, "Los espacios de la patria y la nación en el proyecto político de José Cecilio del Valle", en Anuario de Estudios Centroamericanos, vol. 22 (1), 1996, pp. 41-82.

El Amigo de la Patria, no 18 y 19, t. 2, fol. 139, Guatemala, 30 de noviembre de 1821. 
a fin de alejar de los asociados todo asomo de desconfianza, y de hacer que cada uno obtenga lo que es suyo, goce de iguales derechos y cumpla iguales obligaciones que los demás; y popular, porque siendo la unidad nacional la que se busca y anhela, ha de nacer la idea de las naciones mismas, de los pueblos que las componen, manifestada de manera libre y espontánea, porque sólo así saldrá la expresión de la verdad de los mismos pueblos que desean relacionarse; porque hemos de sentar el principio de que la Unión para que sea efectiva y sincera, debe ser preparada por los pueblos y no por los gobiernos. ${ }^{28}$

Entendía que esta unión se había de realizar desde abajo y desde arriba, simultáneamente; había de unificar ideas y leyes, respetando la pluralidad, dentro de la más amplia tolerancia. La idea de unir a Centroamérica en una sola entidad política era una aspiración nacional, que nada ni nadie debía minimizar; no era patrimonio exclusivo de nadie, sino todo lo contrario, porque con ello se trataba de incluir a todos los partidos, ideas y creencias para evitar que derivase en una simple unión de intereses; además estaba en sintonía con los proyectos de construcción de supranacionalidades del momento. Si alguien se identificaba como dueño de la patente de la unidad estaría destruyendo y contradiciendo la esencia misma del unionismo, que era la idea de pluralidad. En este sentido, todos los ciudadanos se habían de agrupar para llevar a cabo la unión, fuera cual fuera el partido político u opinión propia del bando, porque "ante la magnificencia y la necesidad de la Unión, no tiene razón de ser ningún exclusivismo". ${ }^{29}$ Debían unirse todos los patriotas que deseaban formar la República Federal de Centroamérica.

Mención particular merecen los miembros de la Liga Obrera. La clase obrera era el músculo de los pueblos y también el cerebro en Guatemala, el elemento que daba mayor importancia a la fraternidad como fundamento de la libertad e igualdad de los ciudadanos y los pueblos. El papel activo y protagónico de los obreros en la construcción de la "Madre patria centroamericana" indicaba la aportación del pueblo, como sujeto colectivo que representaba el interés general frente al individuo y sus intereses particulares.

B. Echeverría S., "Consideraciones", en El Unionista, año I, no 15, sábado 31 de enero de 1920.

29 Ibidem. 
Lo primero que había de hacerse en el nivel político era uniformar las leyes de Centroamérica, para que se fundasen en los mismos principios y así armonizar los intereses económicos y financieros, tratando de eliminar los viejos recelos y de evitar viejos y nuevos errores. Además había que conseguir que el ejercicio de los derechos y el cumplimiento de los deberes que atañían a todos se enseñasen a las masas populares, instruyéndolas en el respeto de las leyes, "comenzando por ajustar éstas en un todo armónico y congruente, a los principios modernos del derecho y de la moral, sobre una base esencialmente democrática y republicana", seguía argumentando el unionista B. Echeverría. Había que hacer política de principios, no de personalismos, que eran los que hacían retroceder a los pueblos que luchaban por alcanzar la felicidad. Es interesante el criterio de tolerancia religiosa de este autor, pues explica que, en el deseo de unión de cualquier patriota centroamericano, está presente que sólo si no se produce ninguna clase de injerencia de las cuestiones religiosas individuales y se relegan éstas a la esfera de lo privado, aquélla puede ser consistente y estable.

La unión en un solo pueblo consciente era además un requisito indispensable para poner fin a la marginación de Guatemala del circuito internacional, para romper las cadenas y crecer como ciudadanos. "Unión significa fuerza; y poder es palanca incontrastable para la realización de grandes hechos y consumación de grandes ideales. En un país no se puede concebir la palabra hermosa de puEBLo cuando los ciudadanos no se unen; y no puede haber ciudadanos cuando no hay pueblos".${ }^{30} Y$ es que el pueblo es unión de ciudadanos individualmente considerados, por lo que es la iniciativa individual consciente de querer formar la institución nacional la que impulsa y empuja a la unión centroamericana, la cual conseguirá poner fin a las injusticias; por esto la democracia iba a estimular el fortalecimiento de las clases subordinadas.

El debate entre los mismos unionistas acerca de las prioridades presentaba divergencias. J. Marcos Leiva consideraba que era el

30 Damián Caniz, El Unionista, año I, no 2, jueves 15 de enero de 1920. G. Cardoza, "El crujir de las prensas", en El Unionista, año I, n 17, martes 3 de febrero de 1920. 
patriotismo el que debía preceder a la ciudadanía; en cambio, para Francisco Castañeda Godoy era la conciencia cívica la que debía primar sobre aquél: "La conciencia de la ciudadanía no se forma en el hombre, si éste ignora lo que puede pedir y lo que ha de dar. Lo que políticamente le pertenece y lo que le es ajeno, lo que puede practicar, por ser lícito, y lo que no debe ejecutar por estarle prohibido". ${ }^{31}$ Conociendo previamente la ley, la vida social era más fácil porque las personas y sus costumbres se amoldaban a ella; con las reglas de conducta se conformaban los distintos códigos que eran la base de la legislación de los países y que se hacían positivas por la Constitución de cada uno de ellos. En este sentido, Castañeda aprovechaba las páginas de este periódico para dar unas lecciones de derecho de fácil comprensión para la ciudadanía. Daba una definición interesante y moderna de Constitución de un pueblo:

\begin{abstract}
es el conjunto de leyes especiales que definen su personalidad propia. Es el cuerpo legal que determina las garantías de los ciudadanos para realizar una vida libre. Es la ley que organizando al estado y le señala la ruta de su funcionamiento. Es la voluntad nacional condensada en el más pequeño de los códigos, por sus dimensiones físicas, y el más grande de ellos por su singular origen y su inmensa trascendencia. La Constitución de un país es el alma nacional. Es el espíritu del pueblo. Es un mensaje escrito por Dios para que los hombres sean libres. Es la encarnación de todos nuestros ideales políticos y el camino seguro para llegar a realizarlos. ${ }^{32}$
\end{abstract}

Con la Constitución se frenaba la arbitrariedad, se nivelaban las desigualdades; constituía el arma del ciudadano pacífico. Para los unionistas guatemaltecos, la Constitución era el escudo protector contra los ataques cotidianos, era el azote de los tiranos, que ponía al descubierto su despotismo.

A pesar de que en El Unionista se reiteraba que el debate acerca de que la idea era sobre lo que había que reflexionar, también se dilucidaba sobre qué forma de gobierno había de caracterizar a la Patria Grande.

\footnotetext{
31 Francisco Castañeda Godoy, "Conferencias dominicales", en El Unionista, n 12 , sábado 28 de enero de 1920.

32 Ibidem.
}

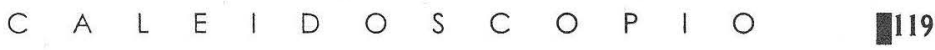


El Partido Unionista atacaba el principio republicano, propugnaba una república amplia, en la cual el sistema bipartidista tradicional debía superarse y la forma de gobierno federal parecía ser la más apropiada. Se rediseñaba un nuevo mapa regional, en el que las cinco repúblicas se transformaban en 19 o 20 regiones, con un distrito federal; se proyectaban nuevas fronteras con criterios más eficaces y prácticos y transformaban la ciudades mayores e históricamente más conflictivas en capitales de provincia. ${ }^{33}$ Además, a diferencia de lo que se había hecho en 1824, se proponía a Guatemala como capital federal, lo que levantó la desconfianza de la periferia. Los unionistas estaban dispuestos a apoyar cualquier medida que favoreciera la unión centroamericana, pero consideraban que la forma federal era la que permitía al ciudadano "consciente" controlar mejor las actuaciones de los gobiernos.

\section{Los ataques a El Unionista}

Las circunstancias obligaron a El Unionista a la sensatez y a la moderación en la expresión de las ideas, para no contravenir las leyes, ya que el objetivo del Partido Unionista y su diario era luchar "por la paz, el derecho y la persuasión, por la unidad de la gran Patria". ${ }^{34}$ Esta moderación le granjeó ataques por parte de otros periódicos que no dudaron en catalogarlo de "cachureco", de conservador. La moderación en las propuestas también le había costado a Valle y a El Amigo de la Patria los mismos calificativos. El Unionista tuvo que afrontar ataques por todos los flancos: La Tribuna, Diario de Centro América, Ilustración Obrera, El Adelanto, El Nacional y críticas al unísono, a pesar de que los unionistas se consideraban auténticos "liberales de corazón y de conciencia", según expresaba en sus páginas L. Alcaín. Por su tolerancia

33 En Colón se incluía la mayor parte de las costas inhóspitas de Honduras y Nicaragua. Las Casas comprendía la amplia y fértil zona septentrional guatemalteca. Granada, Managua y León, viejas y rivales ciudades nicaragüenses, se convertían en capitales de provincia.

El Unionista. Diario Independiente. Organo del partido Unionista, año I, jueves 25 de diciembre de 1919. 
y respeto de los derechos, las ideas, las creencias y los intereses de los demás fueron atacados por los liberales "oficiales", quienes les tacharon de conservadores.

Se defendieron de estos ataques argumentando que no se debería considerar enemigos a quienes profesaban en el fondo la misma idea liberal y trataban de fomentarla. Las diferencias de opinión no eran negativas, pues enriquecían con nuevas ideas un planteamiento de trabajo común. Sin embargo, estas divergencias perdían sentido si venían de los sentimientos negativos del hombre, como la envidia, la cobardía o la ingratitud. Era la inteligencia y la razón lo que debía dominar el mundo; no había que temer a la ley si era justa, sino a la fuerza, que era un crimen contra la ley y la razón.

Los unionistas no se consideraban conservadores, sencillämente porque reputaban que en Guatemala no existía ya esta categoría; de haberlos, no era importante si respetaban la ley, porque también existían en las naciones más grandes, en los países más civilizados y bajo todos los regímenes. El respeto a la ley era el requisito previo a sus ideas de tolerancia. Sostiene Barillas Fajardo que no había espacio en la noble cruzada de la unión para el conservadurismo y el liberalismo, salvo si unidos aportaban sus esfuerzos para hacerla posible de la manera más rápida, completa, solemne y duradera. La Unión centroamericana era una lucha compatible con cualquier partido político, con cualquier idea; la lucha es la vida de los pueblos, el estímulo de progreso y la ley fatal de la civilización. La variedad es consustancial con la naturaleza y así lo debe ser el poder, los partidos, las asociaciones, los hombres, las aptitudes, las razas. Tal variedad no excluía la convergencia hacia el objetivo más conveniente, que era el amor a la Patria, al que debían aspirar y por el que debían luchar todos. Se sentía como una necesidad social, no la de un grupo de personas. Se negaba que existieran liberales, conservadores, radicales o clericales; sólo existía el patriotismo resuelto a hacer posible el ideal al que se oponen sólo los antipatriotas.

Ante la acusación de conservadores, retrógrados y ambiciosos que se hace a los unionistas, Jorge García Granados ${ }^{35}$ aclaraba que los 
verdaderos conservadores habían sido los que en la época de la más asfixiante oligarquía, la de Carrera, cincuenta años antes, sofocaron los gritos de libertad del pueblo, reprobaron la iniciativa individual y encarcelaron al hombre de ideas; se rodearon de fuerza, que es el derecho de los tiranos; abusaron de los cargos públicos con lo que consiguieron fortuna para sí y sus seguidores fieles; penetraron en la Iglesia y mediante la ignorancia y el terror dominaron al pueblo y lo sometieron a su absolutismo. No se podían comparar, decía García Granados, a aquellos conservadores con el Partido Unionista, que animaba a los hombres de buena voluntad, protegía al oprimido, unía al intelectual, al obrero, al estudiante y al propietario en el ideal de la unión y defensa de los derechos y libertades individuales.

Para García Granados el hecho de que en el partido figurasen descendientes de conservadores no significaba que lo fueran; algunos habían representado lo mejor del partido liberal, como Montúfar, hijo y sobrino de serviles; o Miguel García Granados, hijo, sobrino, hermano y cuñado de serviles. Lo importante era que el Partido Unionista estaba compuesto por gente honrada que trabajaba para reconstruir la patria sobre las ruinas de la que habían desmembrado los antepasados a causa de las luchas internas. Igualmente valioso era colocar el derecho como la fuerza mayor y más poderosa. Prueba de que era unitario por encima de todo, los miembros del Partido Liberal consideraban este principio superior a cualquier otro. Esto le había valido también un cierto "transfuguismo", el presidente del Club Liberal, Francisco A. Sánchez Rosal, se había pasado al Partido Unionista, porque aquél era separatista, mientras el nuevo partido estaba integrado por "lo mejor y más granado de Guatemala, sin distinción de partidos políticos ni credos religiosos", gente que trabajaban a favor de la Unión de Centroamérica. ${ }^{36}$ Sin embargo, a pesar de tantas diferencias, había una coincidencia en lo sustancial entre el Club Liberal y el Partido Unionista.

José Rodríguez consideraba deshonestos e irracionales a quienes atacaban a los unionistas, los cuales representaban los ideales de 
nobleza y trascendencia. ${ }^{37}$ Esta dicotomía era expresada con toda claridad: "no hay en el país más que dos partidos: el de los hombres dignos que enarbolan la bandera de la federación y de la Ley y el de los que sostienen la triste bandera del estómago". ${ }^{38}$ La causa de la Unión atraía a los buenos; aún a los que se habían visto obligados a firmar en contra de los unionistas. Todos eran partidarios de la causa del derecho, de la libertad y de la unión de Centroamérica, que aseguraba las otras para siempre y haría que la Patria fuera grande y feliz. Todos los seres humanos habían oído la voz que decía: "todos sois iguales, todos tenéis derecho a ser felices si sois buenos". ${ }^{39}$

Una de las respuestas más duras a los ataques contra el unionismo procede de Reyna Barrios: "los ataques imbéciles de los ignaros caciques y enemigos falsos en su mayoría [...] hojas pletóricas de necedades, que son la prensa de Guatemala, dirigida por la mano convencional de periodistas inhábiles, de espíritu asustadizo e inteligencia venal [...] estos esclavos de mediocridad intelectual".$^{40} \mathrm{Y}$ agregaba que muchos unionistas no comprendían el porqué de tanta oposición si lo que defendían era la verdadera ciudadanía, que es el amor a la patria de los antepasados; si lo que pretendían era moralizar a las masas, que es una de las tareas del buen gobierno, y unificar los partidos era un acierto. La destrucción de las divisiones políticas de liberales y conservadores por la unión perfecta de aquéllas es la labor que se había impuesto el Partido Unionista.

Y si además de regeneradora la idea era también redentora -"lo quiere Dios", "Dios está con nosotros"- la unión haría renacer en la conciencia de los ciudadanos una causa gloriosa, un sentimiento atávico, que resurgía generación tras generación, cada vez más fuerte. Decía José Rodríguez M.: el amor patrio es un grito de fraternidad, que invoca el sacrosanto nombre de la madre, con el que desaparecerán las fronteras,

El Unionista, año l, no 11, martes 27 de enero de 1920.

El Unionista, año I, n 13 , jueves 29 de enero de 1920.

El Unionista, año 1, n० 10, miércoles 26 de enero de 1920.

Humberto Reyna Barrios, "Discurso", en El Unionista, n 17 , martes 2 de febrero de 1920. Cita a Ingenieros en su ataque contra los periodistas interesados. 
las divisiones territoriales y que hará de

cinco agrupaciones irrisorias, una nación fuerte, respetable y libre, en donde cinco millones de hombres den el grande espectáculo de abrazarse fraternalmente encendidos en el amor al bien y en el respeto recíproco que deben presidir en las relaciones de los conciudadanos. ${ }^{41}$

La voluntad nacional se imponía, pues, a la tiranía y al despotismo, desafiaba los peligros y las conciencias esperaban la nueva aurora que les anunciaría la redención. Iba a poner fin a la pantomima ridícula del respeto al derecho. La reacción se imponía como una ley natural. Pueblos y hombres, mujeres y niños sentían ya en sus corazones la fuerza redentora del derecho, la nueva orientación de los principios adoptados por la Constitución; la ley suprema, salvaguardia de las libertades públicas, iba a derrocar a todas las tiranías. Era la Constitución de una nación libre. Si los pueblos tenían una constitución y sus gobiernos la cumplían sin violar la ley, entonces eran pueblos y gobiernos liberales. ${ }^{42}$

Por ello la unión de la vieja patria no era patrimonio de nadie, pertenecía a la humanidad; no se podía monopolizar, pertenecía a todos los centroamericanos. Los hombres eran producto de la época que vivían. Eliseo Solís consideraba constitucional que los unionistas trabajasen directamente por la unión -la Constitución de Guatemala apoyaba la unión siempre que fuera estable, justa, popular y conveniente y no dejase el trabajo exclusivamente en manos de los gobiernos-, pues se trataba de lograr una estabilidad y una justicia que se conseguirían si se pusiera fin a los gobiernos personalistas, se distribuyeran equitativamente los cargos públicos; si cada Estado fuera independiente dentro de la soberanía de la Nación y si fueran los propios centroamericanos los que así lo manifestasen. Se preguntaba: ¿cuándo llegaría el día de la resurrección? ${ }^{43}$ Entonces el pueblo no

41 losé Rodríguez M., "Discurso". en El Unionista, año l, n 11 , martes 27 de enero de 1920.

42 Francisco Castañeda Godoy, "Conferencias dominicales", en El Unionista, año I, nº 12. sábado 28 de enero de 1920 .

${ }^{43}$ Eliseo Solís, El Unionista, n 12, sábado 28 de enero de 1920. 
oiría ya a la prensa calumniadora, porque sabría que en el seno del Partido Unionista había algo más grande que los intereses económicos: el patriotismo, y quienes lo sintieran pedirían redención, patria y libertad. ${ }^{44}$

\section{La unión de Centroamérica en el concierto internacional}

La civilización como otras ideas se definían por la realidad de su puesta en acto. La importancia de tener buenas leyes y respetarlas era lo que diferenciaba a una nación civilizada de la que no lo era. Molina decía:

Naciones hay que marchan a la vanguardia del adelanto, ya en los principios, ya en practicarlos, es decir que tienen leyes y que las cumplen. Otras tienen leyes pero no las cumplen, o las tienen malas. Y, por último, en otras pocas, que más merecen el nombre de tribus, impera sólo la fuerza bruta. llámese a éstas, naciones salvajes o bárbaras; a las primeras civilizadas, a ya las otras semi-bárbaras o semi-salvajes, según sostenía Hostos. ${ }^{45}$

Aunque los pueblos bárbaros y atrasados no llevasen una vida envidiable -porque no reconocían los derechos individuales a sus miembros y se gobernaban por la fuerza los primeros y de forma análoga aunque más mitigada los segundos-, eran mejores que aquellos semibárbaros en los que existían las leyes, pero no se cumplían, porque la política descansaba en la fuerza, la mentira y el engaño. Sin embargo, se presentaban ante las naciones civilizadas y las instancias internacionales como valedoras de esas leyes y esas naciones acababan apoyándoles, cuando en realidad eran naciones semibárbaras porque recortaban los derechos y las libertades, como las de prensa, sufragio y movimiento; mientras que la soberanía de la patria quedaba en manos de quien mandaba, al margen de la ley y el derecho. Debían acabarse las farsas legales porque era una ironía que en el código aparecieran los principios más adelantados de la legislación moderna y éstos se pisotearan continuamente.

Los unionistas veían con desconfianza las injerencias de los países

\footnotetext{
${ }^{44}$ Terencio García, El Unionista, no 16, lunes 2 de febrero de 1920.

${ }^{45}$ El Unionista, año I. no 5 , martes 20 de enero de 1920.
} 


\section{y la tentativa "panamericanista" que se celaba bajo los pactos de}

Washington ${ }^{46}$ y la Oficina Internacional Centroamericana, ${ }^{47}$ interesados en la celebración de una conferencia en 1921, en la que se reanudaba la lucha por la unión federal con motivo de la conmemoración del centenario de la independencia. En este sentido, aprovechaban la

46 El dictador liberal de Nicaragua, José Santos Zelaya, propuso una reunión en 1902 en el Puerto de Corinto para tratar de solucionar los conflictos entre los Estados centroamericanos; Estrada Cabrera de Guatemala se opuso, mientras los restantes acordaron un pacto que permitiera borrar las diferencias, la creación de un tribunal centroamericano que arbitrara los conflictos, salvo los fronterizos, que se encargarían al arbitraje de Estados Unidos. Guatemala manifestó su acuerdo con esto aunque nunca firmó el pacto. El segundo pacto fue en San Salvador en 1903, aceptado por Guatemala pero no por Costa Rica. El tercero fue de nuevo en Corinto en 1904, teniendo como nuevo presidente de Honduras a Manuel Bonilla y con la advertencia de Teodoro Roosevelt de que, de seguir la inestabilidad en la región, se produciría la intervención de alguna nación "civilizada" para pacificar la zona, lo que se hizo en 1906 para poner fin a las hostilidades que desde Honduras y El Salvador se habían desatado contra Estrada Cabrera con el fin de derrocarlo y poner en su lugar al antiguo presidente, $\mathrm{M}$. Lisandro Barillas. En el arbitraje participaron los ministros nortemericanos y mexicanos para Centro América y los observadores de Costa Rica y Nicaragua. Se firmó un tratado de paz temporal con el compromiso de vigilar en los respectivos países la acción de los exiliados. La Conferencia de San José de 1906 no contó con la presencia de Nicaragua, ya que Zelaya se oponía al papel de árbitro de Estados Unidos y sostenía que sin su ayuda también se podía conseguir la unión. En esta reunión se firmó el Pacto de paz, amistad y comercio, confirmó el pacto de Corinto y el Tribunal Centroamericano de Arbitraje, con dos convenciones que se acercaban más al ideal unionista: la creación, a partir de 1907, de la Oficina Internacional Centroamericana con sede en Guatemala, y el Instituto Pedagógico Centroamericano en San José de Costa Rica. Pero los conflictos entre Honduras y Nicaragua estallaron inmediatamente y Honduras, El Salvador y Costa Rica declararon la ruptura del pacto de Corinto, rompiéndose de esta manera los lazos que los unían. Salió vencedor Nicaragua, cuyo presidente Zelaya ayudó a derrocar a Bonilla y los salvadoreños que habían corrido en su ayuda y se preparaba a invadir El Salvador. Para evitar el conflicto regional T. Roosevelt y P. Díaz invitaron a los países centroamericanos a una Conferencia de paz en Washington a finales de 1907, en la que los tres países más grandes previamente habían acordado en Amapala seguir adelante con el proyecto federal. Por parte de Estados Unidos, el representante era Williams I. Buchanan y por la parte mexicana, Enrique Creel. Honduras hizo la propuesta de confederación, con el apoyo de Nicaragua -Zelaya planteó incluso su dimisión, si ello aceleraba la propuesta; Guatemala, en cambio, hizo hincapié en el pacto de amistad de San José, sin ir más allá, con la aquiescencia de Costa Rica y El Salvador. Al máximo había que tratar de fortalecer el comercio, las comunicaciones y los intereses económicos en general, para lo que era fundamental impulsar el Tribunal de Justicia Centroamericano, la Oficina Centroamericana Internacional y el Instituto Pedagógico Centroamericano. Terminó la conferencia con un tratado de paz y amistad y seis convenciones importantes. Era un camino para la confederación, pues se consideraba que la federación no era posible en Centroamérica si seguía existiendo la posibilidad 
coyuntura para atacar a la dictadura de Estrada Cabrera desde posiciones más beligerantes y consiguieron que algunos diputados de la Asamblea se sumaran a sus esfuerzos. Estaba claro que era mejor que la idea de la Unión contara con el respaldo, no sólo de los gobiernos centroamericanos, sino también de Estados Unidos y de América Latina.

Había ya una propuesta en Argentina, precedente a la aparición de El Unionista, que se publicó luego en este periódico, donde se apelaba a que enviasen a sus representantes para apoyar a la unión centroamericana con motivo de la celebración del centenario de la independencia ${ }^{48}$ y se manifestaba el interés de Estados Unidos por dicha unión. Sin embargo, fue en las páginas de El Nacional ${ }^{49}$ donde aparecieron las críticas al unionismo por haber requerido el beneplácito de Estados Unidos, sin haber calculado el peligro que corría la región de que la fagocitase ese imperio. Sin embargo, los unionistas minimizaron en un primer momento la cuestión, pero no olvidaron

de que un estado agrediera a otro. Las conferencias de paz de Washington significaron, pues, paz y confederación mientras la federación fue relegada a tiempos mejores. Estas instituciones se presentaron como foros para la confederación. La Oficina, a pesar de estar en Guatemala capital, redujo sus actividades a preparar una conferencia anual -las hubo desde 1909 a 1914 cada año en una capital- y a editar una revista, Centroamérica, y desapareció en 1923. En relación con Estados Unidos acabaron primando las relaciones bilaterales entre cada país y su vecino del Norte sobre las interestatales o las de arbitraje que se habían contemplado precedentemente. Laudelino Moreno, Historia de las relaciones interestaduales de Centroamérica, Madrid, 1928.

El Unionista, año 1, n 11, martes 27 de enero de 1920. Arturo Peralta A. comenta que según el gobierno, la oficina es la única encargada de representar el ideal unitario y que sin embargo ha paralizado su propaganda por órdenes superiores. El Unionista, año I, no 12, sábado 28 de enero de 1920. Eliseo Solís en cambio, se dirige a la Oficina para demandarle si los pueblos centroamericanos no tienen derecho a trabajar por la unión y si esto es sólo patrimonio de los gobiernos.

La Actualidad, no 261, 20 de diciembre de 1919, traduce un cable del The World de Nueva York: "Buenos Aires, Octubre 3.- La Prensa aboga porque todas las Repúblicas de Sur América acrediten cada una de ellas una Legación ante los cinco Gobiernos de las pequeñas repúblicas de Centro América, en enero de 1920, para que estén ya establecidas al llegar el centenario de la independencia de aquella zona en septiembre de 1921, y cooperen de acuerdo con Estados Unidos, a que formen dichas Repúblicas una sola nacionalidad respetable".

49 F. Quinteros A., "Hay que hablar claro", en El Unionista, año I, nº 17, martes 3 de febrero de 1920 .

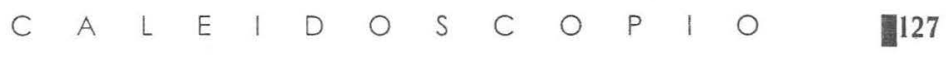


declarar su posición antiimperialista activa. Se aprovechaban de cuantos foros se ponían a su disposición para difundir el proyecto de nación centroamericana. Por ello, alegaban en defensa propia que cualquier espacio público era válido cuando se perseguía construir y defender la Patria Grande de sus antepasados, dentro de la ley, el orden y por los medios eminentemente cultos, a cielo descubierto y pacíficamente. Si se había diseñado y elegido el programa unionista era porque aceptaba todos los credos y todos los partidos, porque creía que en la Unión estaba la grandeza de los pueblos centroamericanos.

El periódico se hizo eco de la fundación de la Liga Internacional de Naciones para mantener la paz de las naciones y mejorar la situación interna de los países, asegurando el goce de los derechos de los ciudadanos. Sostenía al respecto Lara Valdés:

Los horrores de la guerra y el grito de los pueblos oprimidos han sido un llamamiento a la civilización que quiere suprimir las matanzas internacionales y proscribir la arbitrariedad interior. La paz se conseguirá de nación a nación por medio de la Liga de las grandes potencias y la sujeción al Código Internacional; pero hay otra paz, mucho más importante que aquélla y es la paz interior de todas las naciones del globo, que no se alcanza sino por el bienestar de los asociados. Ése es otro de los fines del Congreso de Versalles: el cumplimiento de la Constitución en las repúblicas, el goce de las garantías de los ciudadanos, el imperio del Derecho sobre la haz de la tierra |... el pacto de Versalles impedirá que se diriman en las fronteras las querellas de pueblo a pueblo. ${ }^{50}$

La esperanza en la labor de la Liga de las Naciones como instancia de arbitraje interestatal, al comprometer a los signatarios en la lucha contra la represión, las arbitrariedades y la transgresión del derecho, se presentaba como garantía del respeto a los derechos individuales de los ciudadanos, velaba por sus intereses y el cumplimiento de sus respectivas constituciones, y se presumía que arrojaría de su seno a los gobiernos opresores por considerarlos no civilizados, necesitados aún de tutela y excluidos del comercio amistoso de las grandes potencias.

El Unionista, año I, n० 10, miércoles 26 de enero de 1920. 
La representación guatemalteca del Partido Unionista ante las instancias internacionales, para que actuara junto con los demás unionistas centroamericanos, fue encargada a una comisión integrada por José Barillas Fajardo, designado por la Comisión Directora, José Antonio López, nombrado por la Liga Obrera Unionista, y Óscar Humberto Espada, en representación del Club Unionista Universitario. Se consideraba que los tres representaban al conjunto de las clases sociales presentes en su seno.

El gobierno prohibió la comunicación con las otras repúblicas centroamericanas, trató de acallar a la prensa unionista, perturbó las reuniones, detuvo a algunos de sus miembros y trató a otros "como esclavos y no como a hijos de una nación civilizada, cuyo nombre figura en la Liga de las Naciones". Entre los detenidos figuraba el propio Barillas Fajardo por orden expresa del presidente Estrada Cabrera. ${ }^{51}$ Le sustituyó como representante Federico Castañeda Godoy. Posteriormente también se detuvo a Luis Cobos Batres, prominente ciudadano guatemalteco, lo mismo que todos los demás detenidos. ${ }^{52}$ También fueron encarcelados Tácito Molina y Emilio Escamilla, director y redactor de El Unionista, que fue reemplazado entonces por José Azmitia, a partir del segundo número de febrero de 1920. Ante estas detenciones, el periódico se preguntaba si la nación guatemalteca tenía leyes, libertades y derechos; si se podía considerar o no civilizada. Si no se superaban los localismos no se podía adquirir una dimensión internacional que simbolizaba la fuerza. Sin civilización y sin unión de todos los partidos la meta estaba lejana: "El sentimiento que se hace exclusivo de un partido no puede ser nacional. ¿Lo será internacional? Menos aún."

Formar una nación grande era ventajoso no sólo a nivel internacional, sino también a nivel regional o de la propia América Latina, porque favorecía la formación de ciudadanos civilizados y

Alcance al número 9 de El Unionista del 24 de enero de 1920.

A Jorge García Granados, estudiante de Derecho; a Arturo Saravia y Guillermo Rosales Alcántara, comerciantes; a José Domingo Nájera, Heliodoro Sosa, Guadalupe García, Enrique Batres R., Carlos H. Godoy y Rogelio Flores, agentes 
morales, es decir conocedores de sus derechos, de sus deberes y de las prácticas cívicas; con ello se acabaría con la plaga de los localismos, del dominio de los caciques sobre la población sumisa y obediente. Si se regeneraban las instituciones y se forman ciudadanos conscientes de sus deberes cívicos y de sus derechos personales, la gran nación iba a ser una realidad incontestable.

Conseguido el objetivo inmediato, la caída de Estrada Cabrera, asumió la presidencia Carlos M. Herrera, quien integró a su gabinete a dos unionistas: Adalberto A. Saravia Castillo como ministro de Gobernación y Justicia y Pedro Aguirre Matheu. ${ }^{53}$ El unionismo se convirtió en proyecto hegemónico y vivió sus días de esplendor, se abrieron esperanzas de la conquista de un estado social, con derechos ciudadanos y el triunfo de la Constitución y de las leyes, lo que desembocaría en el progreso irreversible de la región.

El Unionista fue el órgano encargado de la propaganda del ideal centroamericanista que evocaba la Patria Grande de J. C. Valle y lo adaptaba a la realidad centroamericana del momento y a la particularidad guatemalteca; contó con articulistas de gran renombre que supieron, con enorme sencillez, hacer comprensible el ideal supranacional en amplios estratos de la población. Servía además para notificar la represión de la dictadura a los miembros del partido unionista y sus simpatizantes; refería otras ideas y noticias que eran de gran interés para forjar la idea de la gran nación centroamericana.

3

del ferrocarril.

53 El gabinete se completó con: Manuel Arrovo, José A. Beteta, Adrián Vidaurre y Alberto Mencos, todos ellos diputados con Estrada Cabrera. 